\title{
Short-term Wind Power Prediction Technology Research of Poyang Lake Region
}

\author{
Shunhua Zhang ${ }^{1, a^{*}}$, Xiaopin Yang $^{1}$, Zhiying Zhao ${ }^{1}$ \\ ${ }^{1}$ School of Mechanical and Electrical Engineering, Nanchang Institute Technology, Nanchang \\ 330099, China \\ athreehhu@163.com
}

Keywords: Poyang Lake Region, Short-term Wind Power Prediction, Artificial Neural Networks

\begin{abstract}
Artificial neural network(ANN) has very strong robustness and fault tolerance, computing speed is fast, has the self-organizing, self-learning and adaptive ability, and can be fully approximation to arbitrary complex nonlinear relationship, so has been widely used in wind power prediction. This document explains and demonstrates how to get the reasonable prediction results by numerical weather prediction(NWP) mode with ANN. The actual measured data for a wind farm in Poyang Lake in Jiangxi Province is given as an example. The prediction results can meet the requirements of engineering application. So the prediction method has better prediction effect and can guide field operation.
\end{abstract}

\section{Introduction}

Wind energy resources in Jiangxi province is mainly enriched in Poyang lake region. Stable wind energy resources is in northern Poyang lake, the terrain, wind direction, wind power quality is better. According to the geographical position, topography, geomorphology, and the wind resources current situation, the best development areas are Soap lake wind farm, Qingshan wind farm, Laoyemiao (including the Bijia mountain) wind farm, Changling (including DaLing) wind farm, Jishan lake wind farm, Songmenshan wind farm and Jishan wind farm. At present there are five wind farms getting into Jiujiang grid power around the Poyang lake region.

Distribution of multiple wind farms in a larger geographical range, that will greatly reduce the influence of peak output power change by the wind speed and weather peak, the geographical distribution of smoothing effect depends largely on the local climate conditions and the size of the region.

\section{Short-term Wind Power Prediction}

Back Propagation (BP) neural network model has strong adaptability for time series problems that is often used to predict related study. But the traditional BP neural network prediction time is shorter to meet the request accuracy, the error will gradually increase as time goes by[1]. The prediction curve is shown in Fig. 1.

The calculation results of the meteorological data is also as the input of neural network, it can get the prediction results as shown in Fig. 2 with the increase inputs BP neural network. The prediction accuracy have been improved. Compared with the predicted results of Fig. 1, it can see that the precision of prediction results have been improved and accurately predict time is longer. This can explain that increase the inputs related to the wind power can improve the precision of the model.

As the BP neural network has its defects in theory, such as the local minima, the design of neurons in hidden layer [2]. In terms of training data, if the learning sample is small, the neural network learning is not perfect, if too much learning samples, it can make the neural network structure complex. So BP neural network prediction accuracy is not high.

From the above research, the meteorological factors as the input of neural network can improve the prediction precision of the model, improving the structure of network model can avoid the defects 

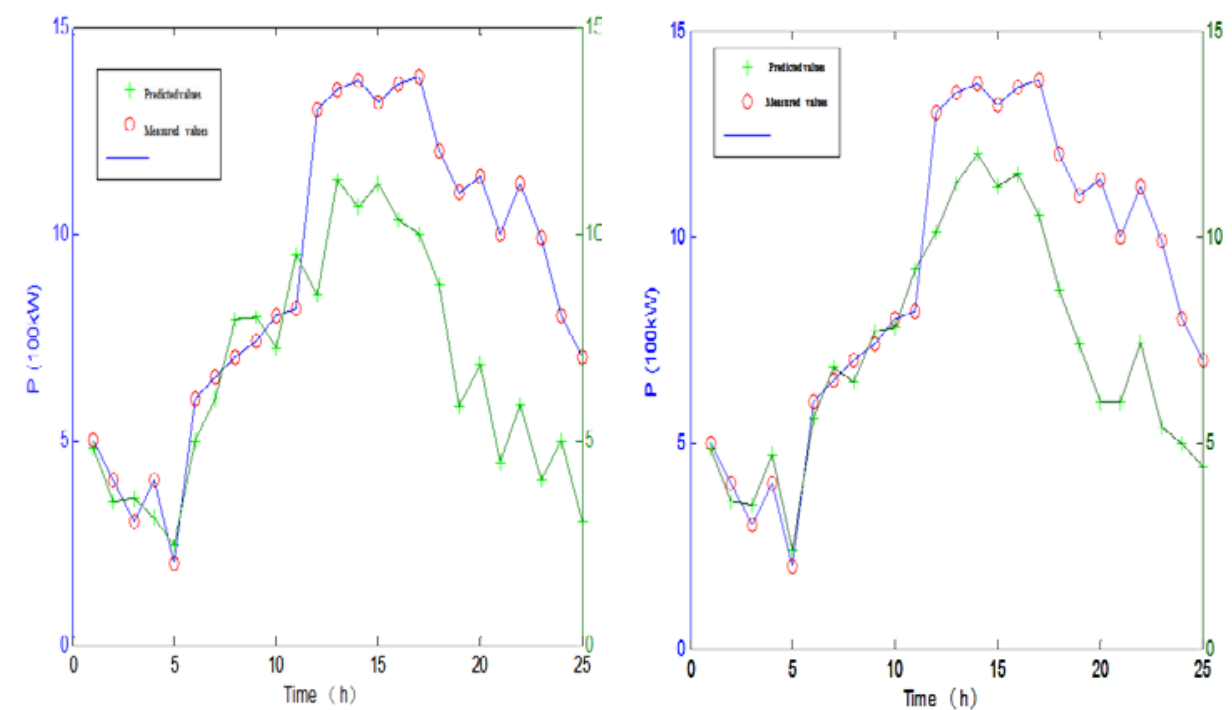

Fig. 1 BP neural network prediction curve

Fig. 2 BP network to increase inputs prediction curve and improve the model prediction accuracy and length of prediction time[3]. Combined with the advantages of both can draw the NWP + ANN prediction model. Model structure is shown in Fig. 3.

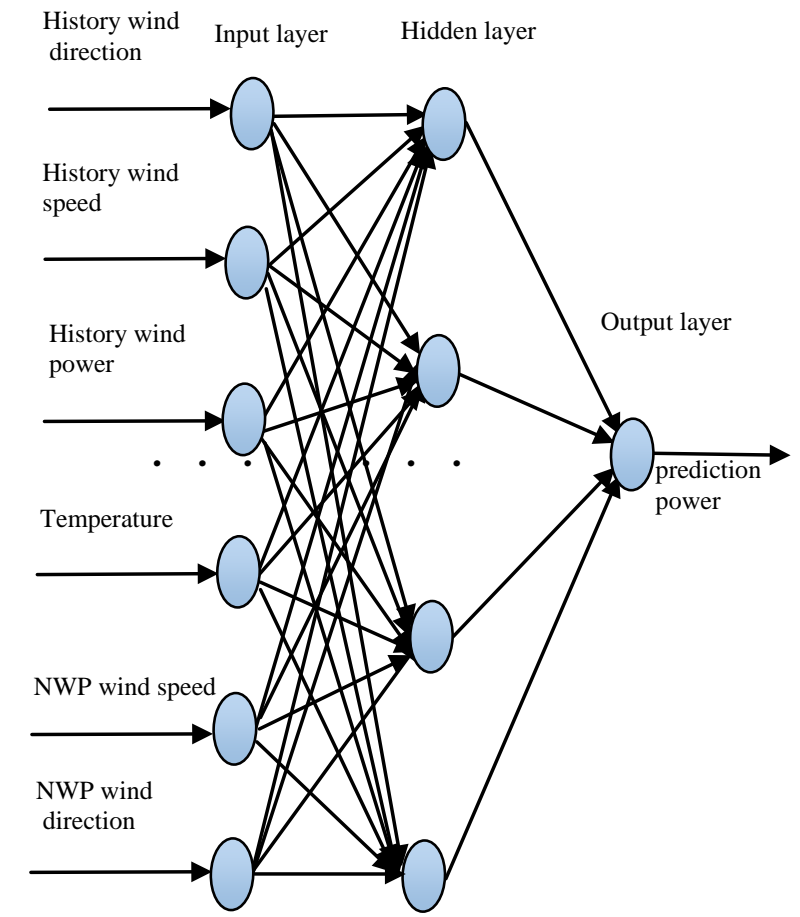

Fig. 3 NWP + ANN prediction model structure

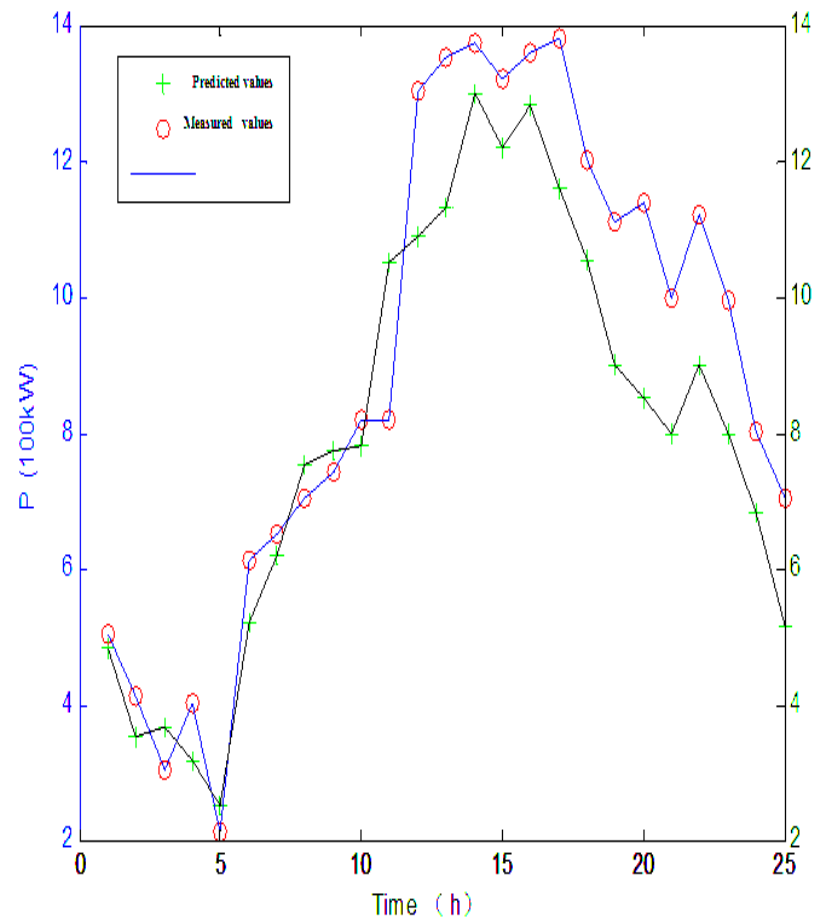

Fig. 4 NWP+ANN network prediction curve

By the prediction results comparison of Fig. 4 shows that the method of NWP+ANN network can greatly improve the accuracy of prediction. NWP + ANN prediction network combined with the numerical prediction model prediction method and the advantages of traditional forecast wind power performance is better than a single numerical prediction model or wind electric power statistical prediction model, the structure can be more effectively to adapt to the working condition of wind farm, automatically reduce the prediction error[4][5]. Even the rare weather conditions, the system can revised forecast to achieve accuracy requirements. 
Tab.1 NWP+ANN predicted results analysis table

\begin{tabular}{cccccccc}
\hline $\begin{array}{c}\text { Value } \\
\text { point }\end{array}$ & $\begin{array}{c}\text { Measured values } \\
(100 \mathrm{~kW})\end{array}$ & $\begin{array}{c}\text { Predicted value } \\
(100 \mathrm{~kW})\end{array}$ & $\begin{array}{c}\text { Error } \\
(\%)\end{array}$ & $\begin{array}{c}\text { Value } \\
\text { point }\end{array}$ & $\begin{array}{c}\text { Measured values } \\
(100 \mathrm{~kW})\end{array}$ & $\begin{array}{c}\text { Predicted value } \\
(100 \mathrm{~kW})\end{array}$ & $\begin{array}{c}\text { Error } \\
(\%)\end{array}$ \\
\hline 1 & 5.02 & 4.81 & -4.18 & 13 & 13.72 & 11.3 & -17.64 \\
2 & 4.11 & 3.52 & -14.4 & 14 & 13.21 & 13.01 & -1.51 \\
3 & 3.03 & 3.66 & -20.08 & 15 & 13.61 & 12.20 & -10.36 \\
4 & 4.01 & 3.19 & -20.45 & 16 & 13.82 & 12.82 & -7.24 \\
5 & 2.12 & 2.52 & 18.87 & 17 & 12.03 & 11.61 & -3.57 \\
6 & 6.11 & 5.21 & -14.73 & 18 & 11.01 & 10.53 & -4.36 \\
7 & 6.52 & 6.20 & -4.91 & 19 & 11.43 & 9.87 & -13.65 \\
8 & 7.05 & 7.51 & 6.38 & 20 & 10.12 & 8.54 & -15.61 \\
9 & 7.41 & 7.72 & 4.18 & 21 & 11.21 & 9.12 & -18.64 \\
10 & 8.21 & 7.81 & -4.87 & 22 & 9.94 & 9.01 & -9.36 \\
11 & 13.02 & 10.5 & -20.45 & 23 & 8.03 & 8.01 & -0.25 \\
12 & 13.51 & 10.9 & -19.32 & 24 & 7.03 & 6.84 & -2.7 \\
\hline 13 & 13.72 & 11.3 & -17.64 & 25 & 6.14 & 5.14 & -16.29 \\
\hline
\end{tabular}

The part of the NWP + ANN prediction error is shown in the Tab.1 below. Since the data is too much, typical point data are listed as follows. Different network prediction error are compared in Tab.2.

Table.2 Different network prediction error comparison table

\begin{tabular}{cccccccc}
\hline $\begin{array}{c}\text { Value } \\
\text { point }\end{array}$ & $\begin{array}{c}\text { BP prediction } \\
\text { error }(\%)\end{array}$ & $\begin{array}{c}\text { Increase inputs } \\
\text { prediction error } \\
(\%)\end{array}$ & $\begin{array}{c}\text { NWP+ANN } \\
\text { prediction error } \\
(\%)\end{array}$ & $\begin{array}{c}\text { Value } \\
\text { point }\end{array}$ & $\begin{array}{c}\text { BP prediction } \\
\text { error }(\%)\end{array}$ & $\begin{array}{c}\text { Increase inputs } \\
\text { prediction error } \\
(\%)\end{array}$ & $\begin{array}{c}\text { NWP+ANN } \\
\text { prediction error } \\
(\%)\end{array}$ \\
\hline 1 & -4.0 & -2.9 & -4.18 & 13 & -16.29 & -16.29 & -17.64 \\
2 & -12.5 & -10.25 & -14.4 & 14 & -22.4 & -12.41 & -1.51 \\
3 & 19.6 & 16.6 & -20.08 & 15 & -15.15 & $-15.12-$ & -10.36 \\
4 & -22.5 & 17.5 & -20.45 & 16 & -23.91 & -15.44 & -7.24 \\
5 & 24.2 & 19.21 & 18.87 & 17 & -27.5 & -23.92 & -3.57 \\
6 & -16.67 & -6.67 & -14.73 & 18 & -32.73 & -27.5 & -4.36 \\
7 & -7.69 & 4.62 & -4.91 & 19 & -47.37 & -32.73 & -13.65 \\
8 & 12.86 & -7.64 & 6.38 & 20 & -40.0 & -47.37 & -15.61 \\
9 & 7.72 & 4.05 & 4.18 & 21 & -55.36 & -40.0 & -18.64 \\
10 & -10 & -2.51 & -4.87 & 22 & -47.58 & -33.57 & -9.36 \\
11 & 15.85 & 12.12 & -20.45 & 23 & -59.59 & -45.59 & -0.25 \\
12 & -34.62 & -21.54 & -19.32 & 24 & -37.5 & -37.5 & -2.7 \\
13 & -16.29 & -16.29 & -17.64 & 25 & -57.14 & -37.14 & -16.29 \\
\hline
\end{tabular}

\section{Summary}

From NWP + ANN prediction error analysis, it can see that the overall prediction accuracy is above $80 \%$, is better than the $70 \%$ prediction accuracy before, the forecast effect is superior much more. In addition to the two days of maintenance equipment, forecast error is caused by the outside, the else prediction results can meet the requirements of engineering application. So the prediction method have better prediction effect and can guide field power grid operation. 


\section{Acknowledgment}

This work was financially supported by the Jiangxi Natural Science Foundation (20114BAB206036), the Science and Technology Project of Jiangxi Province Education Department (GJJ13769).

\section{References}

[1] Weiping Luo, Jianxin Zou. Weather sensitive for MATLAB neural network application in wuhan district power network short-term load prediction [J]. Electric power construction, 2003, 24 (2): 30-34.

[2] Yanxi Yang, Ding Liu, Qi Li, Gang Zheng. Neural network short-term load forecasting based on BP - GA hybrid learning algorithm [J]. Journal of information control, 2002, 31 (3): 284-288.

[3] Bakirtzis A to G, Petridis V, Kiartzis S J et al. A Neural Network Short Term Load Forecasting Mode for the Greek Power systems [J]. IEEE Trans on Power systems, 1996, 11 (2): 858-863.

[4] Han Shuang. Short-term wind power prediction method research. Beijing: North China Electric Power University, 2008.

[5] Zhi Li, Xueshan Han, Li Han,et al. An ultra short term wind power forecasting method in regional grids. Automation of Electric Power Systems,2010,34(7):90-94. 